surgeries for hand or foot disorders have been increasing. However, it is unclear about the surgery for cervical spine disorder.

Objectives: We clarified the change in the surgical treatments for cervical spine disorder related to RA patients at our institution.

Methods: From 2001 to 2015 , we identified 71 RA patients with a cervical spine surgery. The mean age was 65.4 years (range, 44-90 years). The patients consisted 11 males and 60 females. The mean disease duration was 20 years (range, 0-52 years). They were classified into three subgroups according to the affected level: the upper lesions (UL) such as atlantoaxial subluxation, the middle and lower lesions (MLL) including subaxial subluxation, and the expanded lesions (EL) which have both features. Individual groups were assessed the change of the number of surgical treatment. In addition, we divided the period into first seven years (from 2001 to 2007) and last eight years (from 2008 to 2015), and compared each other.

Results: There were 38 patients in UL, 25 patients in MLL and 8 patients in EL. Most patients in UL were underwent atlantoaxial fixation by Magerl and Brooks procedure, and the number of them was constant throughout the entire period. Occipito-cervical fusion has been decreasing. Although there were much surgeries of MLL disorder in last 8 years than that in first 7 years, most of them did not have RA change such as endplate erosion and subluxation.

Conclusions: There was no significant change in EL throughout all periods. In conclusion, surgeries for cervical spine disorder of RA patients remained in our institute. However, disorders related to RA within them, especially MLL, were decreasing. it indicates that expansion of RA remission has led to the reduction of cervical spine surgeries with RA change.

Disclosure of Interest: None declared

DOI: 10.1136/annrheumdis-2017-eular.1156

\section{AB0940 EFFICACY AND SAFETY OF PLATELET RICH PLASMA PERI-NEURAL INJECTION IN TREATMENT OF DIABETIC NEUROPATHY: DOUBLE BLIND RANDOMIZED CONTROLLED TRIAL}

M. Hassanien ${ }^{1}$, Y. Saad ${ }^{1}$, A. Alawamy ${ }^{2}$, W.A. Khalifa ${ }^{3}$, D. Abdelkarem ${ }^{4}$. ${ }^{1}$ Rheumatology Department; ${ }^{2}$ Anathesia department Assuit university; ${ }^{3}$ Internal Medicine; ${ }^{4}$ Clinical Pathology, Assuit University, assuit, Egypt

Background: Neuropathy is a common complication of diabetes mellitus (DM) not only leads to an impaired quality of life, but also to an increased morbidity and mortality.Autologous platelet-rich plasma is easy and cost-effective method. Platelet-derived angiogenesis factor capable of stimulating new capillary growth by inducing migration of endothelial cells, influence the process of angiogenesis and revascularisation.

Objectives: evaluate the clinical efficacy and safety of perineural PRP injection in the treatment of diabetic neuropathy (DN) compared to tradition medical treatment.

Methods: Sixty patients were selected from Endocrinology unit Department of Internal medicine, Assuit university Hospital, Egypt had type II diabetes mellitus neuropathy (DN) of at least 5 years duration of symptoms, regardless of age and gender double blindly divided into two groups, both groups had control blood glucose. Group I underwent PRP preineural injection under ultrasound guidance and group II underwent medical treatment. Baseline pain and nerve conduction study of upper and lower limb nerves and sural nerve conduction studies, F-wave. nerve conduction study were determined at 3 months after the procedure. Primary outcome was the total effective rate. The total effective rate $=$ (the number of patients with significant effect+ the number of patients with effect)/total number of patients. A "significant effect" meant that limb pain, numbness, and fatigue were significantly reduced, nighttime sleep was improved, and NCV from electromyography increased $>5 \mathrm{~m} / \mathrm{s}$ or returned to normal. An "effect" meant that the symptoms mentioned above were relieved, and NCV compared with pre-treatment increased $<5 \mathrm{~m} / \mathrm{s}$. "Failure" meant that the symptoms did not improve, and there were no changes in NCV electromyography

Results: We recruited 60 diabetic patients (type II) with peripheral neuropathy with a mean age $35.27 \pm 12.86$ years with disease duration of $7.42 \pm 3.51$ years. Of these, $56 \%$ cases with upper limb nerves neuropathy only while the rest $44 \%$ had sural nerve plus upper limb nerves neuropathy. Nerve conduction study showed axonal affection in only $26 \%$ and all had delayed distal latency and prolonged motor conduction velocities. generalized DN is found in $70 \%$ of total patients and $30 \%$ of had focal Entrapment of the nerve includes median neuropathy at the wrist $50 \%$, ulnar neuropathy at the elbow $30 \%$ and peroneal neuropathy at the knee $20 \%$ and no patients had radiculoplexus neuropathies.

\begin{tabular}{|c|c|c|c|}
\hline & \multicolumn{2}{|c|}{ Group I } & \multirow[t]{2}{*}{ P-value } \\
\hline & Baseline & 3 months Post injection & \\
\hline Mean motor NCV $\pm S D$ & $35.6 \pm 12.67$ & $46.38 \pm 10.68$ & $\leq 0.05^{\star}$ \\
\hline Mean $\mathrm{DL} \pm \mathrm{SD}$ & $9.19 \pm 8.16$ & $4.55 \pm 5.66$ & 0.09 \\
\hline \multirow[t]{2}{*}{ Sural conduction velocity } & $17.00 \pm 10.86$ & $34.00 \pm 6.84$ & $\leq 0.001^{\star \star}$ \\
\hline & Group I & Group II & $\mathrm{P}$-value \\
\hline Effect & $85.47 \pm 9.91 \%$ & $79.38 \pm 12.40 \%$ & 0.16 \\
\hline Significant effect & $95.29 \pm 15.28 \%$ & $81.00 \pm 9.64 \%$ & $\leq 0.001^{\star \star}$ \\
\hline Total effective rate & 22/30 (73.3\%) & $11 / 30(36.6 \%)$ & $\leq 0.05^{\star}$ \\
\hline Failure & $7.00 \pm 2.86 / 30$ & $18.00 \pm 2.84 / 30$ & $\leq 0.001^{\star \star}$ \\
\hline
\end{tabular}

Conclusions: Autologous platelet-rich plasma is an easy and cost-effective method as a treatment of diabetic peripheral neuropathy.

Disclosure of Interest: None declared

DOI: 10.1136/annrheumdis-2017-eular.1272

\section{AB0941 PATIENTS PROFILE AT ORTHOGERIATRIC UNIT: NEW MODEL OF CARE}

S. Hammami, A. Meziani, A. Ioana, C. Dumont, V. Latteur. Geriatric, GHdC Belgium, Charleroi, Belgium

Background: Fractures in elderly patients its a prevalent problem. Older patients due their characteristics requires a specific care. The orthogeriatric Unit has been shown to be one of the most beneficial units. It is important to evaluate the model of care

Objectives: Evaluate the main variables of fractures patients treated at a orthogeriatric Unit and their complications

Methods: This is a partially concurrent prospective study, taking place in a large urban academic hospital GHdC in Belgium. The participants were 87 consecutive elderly people, admitted directly to a geriatric-based orthogeriatric ward.

Results: A total of 87 patients were included. The average age was $85.2 \pm 5.2$ years, 20 male, 67 female. Most of them $(n=44,52 \%)$ were admitted for a hip fractures, $44 \%(n=38)$ were transferred from emergency department, ISAR score was $3.9 \pm 1.1$, Preoperative stay was less than $24 \mathrm{~h}$ for $54 \%$ of our population, Mini nutritional assessment was $18.7 \pm 4.3$, Mini mental state examination was 20.6 \pm 6.4 , the Cumulative IIIness Rating Scale was $17.1 \pm 4.5$, the mean number of medicine was $6.8 \pm 3.3$, Activity of Daily Living 15 days after admission was 12.2 \pm 5.5 . Delirium was the principal complication $55 \%(n=44)$. Mean hospital stay between admission and discharge/transfer to convalescence unit was $23.8 \pm 12.9$. In-hospital mortality was $11 \%(\mathrm{n}=10)$

Conclusions: Fractures is a frequent and disabling pathology among geriatric fragile population, its treatment requires an interdisciplinary approach. This must be managed by the collaboration between geriatrician and orthopedist. We believe that the orthogeriatric Unit providing subacute and acute care will improve the general outcome of fragile geriatric patients

References:

[1] González-Montalvo Jl et al The orthogeriatric unit for acute patients: a new model of care that improves efficiency in the management of patients with hip fracture. Hip Int. 2010 Apr-Jun;20(2):229-35.

[2] Smith TO et al Factors predicting incidence of post-operative delirium in older people following hip fracture surgery: a systematic review and meta-analysis. Int J Geriatr Psychiatry. 2017 Jan 17.

Acknowledgements: Geriatric multidisciplinary team working in GHdC Charleroi Belgium.

Disclosure of Interest: None declared

DOI: 10.1136/annrheumdis-2017-eular.5845

\section{AB0942 EFFECT OF CORTICOSTEROID INFILTRATIONS ON DIABETES. A MONOCENTRIC RETROSPECTIVE STUDY}

S. Mathieu, M. Couderc, Z. Tatar, J. Lopez, S. Malochet-Guinamand,

J.-J. Dubost, A. Tournadre, M. Soubrier. Rheumatology, CHU Gabriel Montpied, Clermont-Ferrand, France

Background: Corticosteroid therapy can unbalance diabetes, particularly when administered orally, but also during articular infiltration. Corticosteroid infiltrations are an integral part of the therapeutic arsenal in rheumatology. They are utilized to treat congestive articular flare-ups of osteoarthritis or inflammatory rheumatic diseases. Periarticular or ductal pathologies, such as trochanteric bursitis, rotator cuff pathology and carpal-tunnel syndrome, may require the use of these infiltrations. Caution is often required when using corticosteroid infiltrations in diabetics.

Objectives: The purpose of our study was to evaluate whether or not diabetic patients undergoing a corticosteroid infiltration during hospitalization had a diabetes imbalance.

Methods: Diabetic patients having undergone a corticosteroid infiltration during hospitalization between 2009 and 2015 were sought. We collected data regarding their rheumatological pathology, glycated hemoglobin $(\mathrm{HbA} 1 \mathrm{c})$, and fasting glycemia on the day of the infiltration, the next day and after 48 hours.

Results: A total of 114 patients were included in our study. The average age was $72.1 \pm 9.4$ years. All of them had Type 2 diabetes, and 35 of them were treated with insulin. Average $\mathrm{HbA} 1 \mathrm{c}$ was $7.3 \pm 0.1 \%$. Overall, $47(41.2 \%)$ patients had an $\mathrm{HbA} 1 \mathrm{c}$ below $7 \%$. A total of $31(27.2 \%)$ patients had a diabetes imbalance after infiltration, and 19 of these, who were taking oral antidiabetics, required 48 hours of rapid insulin to balance their glycemia. Overall, 12 patients increased their insulin dose. Out of the 47 patients with good HbA1c, 7 (14.9\%) of them had a glycemia imbalance, versus $24(35.8 \%)$ who were unbalanced out of the 67 patients whose $\mathrm{HbA1c}$ exceeded $7 \%(\mathrm{p}=0.013)$.

Conclusions: Corticosteroid infiltrations can lead to a diabetes imbalance, thus making it necessary to administer a few days of rapid insulin or to increase the insulin dose. A patient whose $\mathrm{HbA1c}$ is below $7 \%$ has a low risk of unbalancing his/her diabetes after corticosteroid infiltration.

Disclosure of Interest: None declared 
DOI: 10.1136/annrheumdis-2017-eular.2918

\section{AB0943 SIGNIFICANCE OF MUSCLE VOLUME \& FATTY DEGENERATION OF LUMBAR PARASPINAL MUSCLE IN SPINAL IMBALANCE}

Y.-S. Park, J. Lee, J.-S. Park. Department of Orthopaedic Surgery, Hanyang University Guri Hospital, Guri city, Korea, Republic Of

Background: Spinal sagittal imbalance which is closely associated with low back pain is considered as a factor in a variety of spinal disorders.

Objectives: The present study was to determine the relationship between the sagittal imbalance and sarcopenia, especially cross sectional area (CSA) and fatty degeneration (FD) of muscle around the spine.

Methods: Overall, 165 patients are included in this study, classified by three groups according to the distance from sagittal vertical axis to posterior end of upper end plate of sacrum.

38 patients were classified as group 1 (distance $\geq 9 \mathrm{~cm}$ ), 50 and 53 patients as group 2 (distance $5-9 \mathrm{~cm}$ ) and group 3 (distance $<5 \mathrm{~cm}$ ), respectively. For measurement of CSA and FI of paraspinal muscles, five transverse T1W images of S1-S5 were obtained from PACS and measured with Adobe Photoshop 7.0 ${ }^{\circledR}$, by counting the number of pixels included in each selected muscle area. A variance analysis on average muscle surface area of those five images was done with SPSS 19.0 Windows version (SPSS Inc., Chicago, IL, USA).

Results: The average age of total patients was 69.1, average BMI was 22.57 and bone density was -2.34 (T-score)

No significant differences were detected on ages, BMI, and bone density. Each correction coefficient of multifidus, erector spinae and psoas muscle was 0.80 , 0.75 and 0.81 , respectively.

CSA of paraspinal muscles has significant differences between group I and III, II and III. Psoas has significant differences between all groups. FI has significant differences between all groups in multifidus and between I and III, II and III in erector spinae. But, psoas has no significance between three groups.

Conclusions: Authors were able to detect significant muscle atrophy in the group with severe imbalance. And degeneration of paravertebral muscle has significant increased with sagittal imbalance. Effort for preventing weakness of muscle around spine might cause influence to alignment of spine.

\section{References:}

[1] Fortin M, Lazáry À, Varga PP, McCall I, Battié MC. Paraspinal muscle asymmetry and fat infiltration in patients with symptomatic disc herniation. Eur Spine J Off Publ Eur Spine Soc Eur Spinal Deform Soc Eur Sect Cerv Spine Res Soc 2016;25:1452-9. doi:10.1007/s00586-016-4503-7.

[2] Lee SH, Park SW, Kim YB, Nam TK, Lee YS. The fatty degeneration of lumbar paraspinal muscles on computed tomography scan according to age and disc level. Spine J Off J North Am Spine Soc 2016

[1] doi:10.1016/j.spinee.2016.08.001.

Disclosure of Interest: None declared

DOI: 10.1136/annrheumdis-2017-eular.4228

\section{Paediatric rheumatology}

\section{AB0944 USE,SAFETY AND EFFICACY OF ETANERCEPT IN JIA-A SINGLE CENTRE RETROSPECTIVE STUDY FROM NORTH INDIA}

A. Shivpuri ${ }^{1}$, S. Mittal ${ }^{1}$, M. Agarwal ${ }^{2}$, S. Sawhney ${ }^{2} .{ }^{1}$ Fellow in Training, Pediatric Rheumatology; ${ }^{2}$ Consultant, Sir Ganga Ram Hospital, New Delhi, India

Background: The treatment paradigm for Juvenile Idiopathic Arthritis (JIA) has changed in last decade:Early diagnosis,objective assessment \& appropriate use of biologic response modifiers (BRMs) are common place.Etanercept (Et) is available in India for 15yrs. BRM use in developing world is fraught with challenges: cost, high burden of Tuberculosis (TB) \& retention. In view of the cost \& safety concerns regarding TB, at our centre, full dose Et is used for 3-6 mths, followed by dose tapering as tolerated.

Objectives: 1. To determine the use, safety \& efficacy of Et in JIA. 2. To determine the factors that determine responders vs non responders. 3 . To determine the factors that determine disease free survival on stopping Et

Methods: This study was done from 15thJune'15 to15thDec'16 (18mths) at Sir GangaRam Hospital. Inclusion criteria: All JIA pts who took Et for min 12 wks \& attended the outpatients during the study period. Outcome: All pts who achieved the Wallace criteria of inactive ds, clinical remission on (CRoM) or off medication within 4 months were termed as responders.

Results: Use: 46pts recd Et (29M,17F). Median (Md) age at JIA onset: 9.08yrs (1.16-16.5).Md delay to diagnosis: 4 mths (0.5-63). Md age at initiation of Et: 11.6yrs (4.25-20.3). Indications: Partial response to Intraarticular steroids/bridging steroids \& DMARD-32; Started upfront for high ds.burden: 14. Diagnoses: ERA30 (65\%), Poly JIA8 (17\%), OJIA 3 (7\%), SOJIA $3(7 \%)$ \& UJIA $2(4 \%)$. Safety: Screening: Mantoux +ve: 6, Quantiferon+ve: 2, antitubercular therapy for latent TB: 8. Side effects: 41 (88\%) had no adverse event. 5 pts - 1 each had enteric fever, varicella, uveitis, hemolysis, malaria. Follow up: Md duration of follow up-47.5 mths (2-147). Medications at last follow up: Et ongoing in 20 (43.5\%), 12 on 2nd BRM, 12 off BRM \& 2 lost to follow up. Status at last follow up: Of 37 responders -8 currently active.
Responders vs non responders: 37 responded ( 2 excluded duration $<12$ wks). In all responders drug was tapered/stopped. No demographic, clinical, lab criteria could predict responder from non responder (Table 1).

\begin{tabular}{lccc}
\hline & Responders (37/44) & Non Responders (7/44) & p value \\
\hline Md time to inactivity post Et & 9 wks $(1-52)$ & - & \\
Md time to flare & $15 \mathrm{~m}(3-63)$ & - & \\
Md duration of taking Et & $18 \mathrm{~m}(3-56)$ & $5.5 \mathrm{~m}(2-22)$ & 0.01 \\
Md Time to first taper Et & $5 \mathrm{~m}(1-34)$ & $2 \mathrm{~m}(1.5-16)$ & 0.44 \\
Median ESR & $38(4-125)$ & $63(22-125)$ & 0.08 \\
SJC $\leq 4$ jts $>4$ jts & $29(78.4 \%) 8(21.6 \%)$ & $4(57.1 \%) 3(42.9 \%)$ & 0.34 \\
TJC $\leq 4$ jts $>4$ jts & $32(86.5 \%) 5(13.5 \%)$ & $4(57.1 \%) 3(43 \%)$ & 0.10 \\
\hline
\end{tabular}

Of 37 responders, 15 (40.5\%) did not show any flare (Table 2$)$

\begin{tabular}{lccc}
\hline & Flared (22/37) & Never flared (15/37) & p value \\
\hline Md time to inactivity post Et & 11 wks $(1-36)$ & 6 wks $(2-52)$ & 0.43 \\
Md time to flare & $15 \mathrm{~m}(3-63)$ & $18 \mathrm{~m}(3-33)$ & 0.74 \\
Md duration of Et & $17.5 \mathrm{~m}(3-53)$ & $25 \mathrm{~m}(6-56)$ & 0.64 \\
Md Time to first taper & $5.5 \mathrm{~m}(1-12)$ & $4 \mathrm{~m}(2-34)$ & 0.58 \\
Md time to stop steroids & $3 \mathrm{~m}(1-12)$ & $2 \mathrm{~m}(1-4)$ & 0.16 \\
Median ESR & $28(4-120)$ & $45(15-125)$ & 0.29 \\
$\mathrm{SJC} \leq 4$ jts $>4$ jts & $17(77.3 \%) 5(22.7 \%)$ & $12(80 \%) 3(20 \%)$ & 1 \\
$\mathrm{TJC} \leq 4$ jts $>4$ jts & $19(86.4 \%) 3(13.6 \%)$ & $13(86.7 \%) 2(13.3 \%)$ & 1 \\
\hline
\end{tabular}

Disease free survival on Et: Of 37 responders, 22 flared. No factors could predict flare in pts who recd tapering Et dose or after stopping Et. Some needed repeat cycles of Et/2nd BRM. Kaplan Meier curve of responders confirmed that no pt would be flare free at $63 \mathrm{mth}$ of follow up.

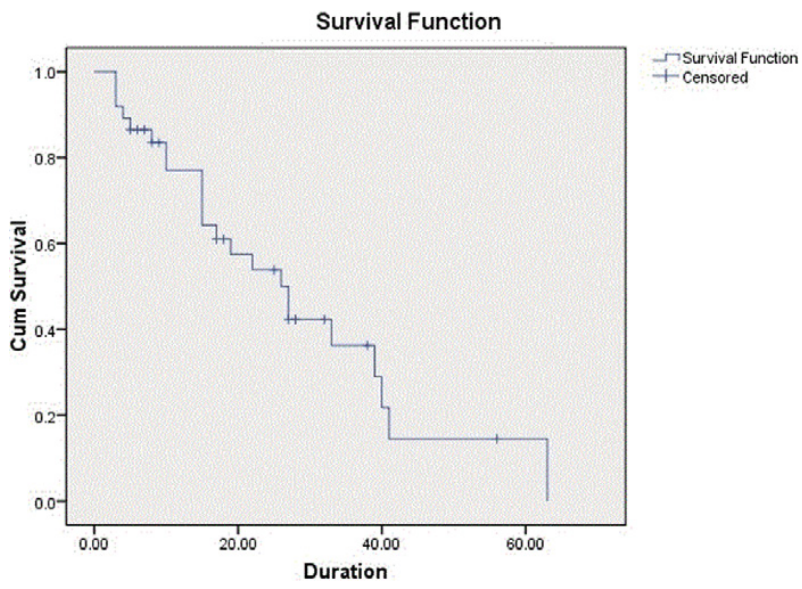

Conclusions: Et is safe to use \& had no adverse events in $89 \%$. Needed most for ERA. Effective in $84 \%$. On using shortterm Et, $59 \%$ flared either on tapering/stopping. These pts responded to reinitiation of Et/BRM. On long term follow up (63mth) there were no flare free pts.

Disclosure of Interest: None declared

DOI: 10.1136/annrheumdis-2017-eular.4892

\section{AB0945 COHORT STUDY OF 112 PATIENTS WITH JUVENILE IDIOPATHIC ARTHRITIS DURING TRANSITION FROM PEDIATRIC TO ADULT CARE}

A.-C. Debrach ${ }^{1}$, A. Beaumel ${ }^{2}$, A. Rougelot ${ }^{2}$, J.-P. Larbre ${ }^{2}$, M. Couret $^{1}$, F. Coury ${ }^{2} \cdot{ }^{1}$ Rheumatology, CHUV, Lausanne, Switzerland; ${ }^{2}$ Rheumatology, HEL, Lyon, France

Background: Juvenile idiopathic arthritis (JIA) is the most common chronic inflammatory arthritis in children. The International League of Associations for Rheumatology 2001 (ILAR) classification includes 7 subgroups: systemic JIA, polyarticular JIA, oligoarticular JIA, enthesitis related arthritis (ERA), psoriatic arthritis and undifferentiated arthritis. Most paediatric inflammatory arthritides persist into adulthood. Therefore, a transition from paediatric to adult rheumatology is a necessary step. Transition is defined as an active process by which a young patient with a chronic disease develops skills and resources to gradually take control of their condition. The transition phase should be anticipated and structured because of the risk of failure in monitoring. However difference in classification criteria in paediatric and adult rheumatology can cause significant difficulty for adult rheumatologists.

Objectives: The aim of this study was to determine the characteristics of juvenile-onset arthritis seen during the transition period and to compare paediatric classification criteria to those of adults.

Methods: A retrospective bi-centre study was performed. Patients with JIA according to ILAR classification were included and had a consultation at transition. JIA classification criteria were compared to ACR/EULAR 2010 criteria 